\title{
Strain and strain rate by two-dimensional speckle tracking echocardiography in a maned wolf ${ }^{1}$
}

\author{
Matheus M. Mantovani ${ }^{2}$, Adriana C. Silva ${ }^{2 *}$, Ruthnéa A.L. Muzzi ${ }^{2}$, Guilherme \\ Oberlender $^{2}$, Rosane M. Resende ${ }^{2}$, Leonardo A.L. Muzzi², Antonio C.C. Lacreta Junior ${ }^{2}$ \\ and Rodrigo B. Nogueira ${ }^{2}$
}

\begin{abstract}
Mantovani M.M., Silva A.C., Muzzi R.A.L., Oberlender G., Resende R.M., Muzzi L.A.L., Lacreta Junior A.C.C. \& Nogueira R.B. 2012. Strain and strain rate by twodimensional speckle tracking echocardiography in a maned wolf. Pesquisa Veterinária Brasileira 32(12):1336-1340. Setor de Clínica Médica de Pequenos Animais, Serviço de Cardiologia Veterinária, Departamento de Medicina Veterinária, Universidade Federal de Lavras, Campus Universitário s/n, Caixa Postal 3037, Lavras, MG 37200-000, Brazil. E-mail: adrianagudi@gmail.com

The measurement of cardiovascular features of wild animals is important, as is the measurement in pets, for the assessment of myocardial function and the early detection of cardiac abnormalities, which could progress to heart failure. Speckle tracking echocardiography (2D STE) is a new tool that has been used in veterinary medicine, which demonstrates several advantages, such as angle independence and the possibility to provide the early diagnosis of myocardial alterations. The aim of this study was to evaluate the left myocardial function in a maned wolf by 2D STE. Thus, the longitudinal, circumferential and radial strain and strain rate were obtained, as well as, the radial and longitudinal velocity and displacement values, from the right parasternal long axis four-chamber view, the left parasternal apical four chamber view and the parasternal short axis at the level of the papillary muscles. The results of the longitudinal variables were $-13.52 \pm 7.88,-1.60 \pm 1.05$, $4.34 \pm 2.52$ and $3.86 \pm 3.04$ for strain (\%), strain rate $(1 / \mathrm{s})$, displacement (mm) and velocity $(\mathrm{cm} / \mathrm{s})$, respectively. In addition, the radial and circumferential Strain and Strain rate were $24.39 \pm 14.23,1.86 \pm 0.95$ and $-13.69 \pm 6.53,-1.01 \pm 0.48$, respectively. Thus, the present study provides the first data regarding the use of this tool in maned wolves, allowing a more complete quantification of myocardial function in this species.
\end{abstract}

INDEX TERMS: Cardiac function, Chrysocyon brachyurus, maned wolf, systolic function, wild canid.

RESUMO.- [Strain e strain rate por meio de ecocardiografia speckle traking bidimensional em um lobo-guará.] A obtenção de parâmetros cardiovasculares em animais selvagens são importantes de serem avaliados, assim como em animais de companhia, para a obtenção da função miocárdica e determinação precoce de alterações cardíacas que poderiam evoluir para insuficiência cardíaca. A ecocardiografia speckle tracking (2D STE) é uma ferramenta nova que tem sido utilizada em medicina veterinária, a qual tem demonstrado várias vantagens quanto ao seu uso, como a

\footnotetext{
${ }^{1}$ Received on March 13, 2012.

Accepted for publication on September 1, 2012.

2 Setor de Clínica Médica de Pequenos Animais, Serviço de Cardiologia Veterinária, Departamento de Medicina Veterinária, Universidade Federal de Lavras, Campus Universitário s/n, Cx. Postal 3037, Lavras, MG 37200000, Brazil.*Corresponding author: adrianagudi@gmail.com
}

independência do ângulo de insonação e a possibilidade de se obter o diagnóstico precoce de alterações miocárdicas. Objetivou-se avaliar a função miocárdica esquerda de um lobo guará por meio do uso da 2D STE. Desta forma, foram obtidas as variáveis Strain e Strain Rate longitudinais, circunferenciais e radiais, assim como a velocidade e o deslocamento longitudinais e radiais, utilizando os cortes eixo longo paraesternal direito quatro câmaras, paraesternal esquerdo apical quatro câmaras e eixo curto paraesternal direito no plano dos músculos papilares. Os resultados das variáveis longitudinais fora $-13,52 \pm 7,88,-1,60 \pm 1,05$, $4,34 \pm 2,52$ e $3,86 \pm 3,04$ para Strain (\%), Strain rate $(1 / \mathrm{s})$, deslocamento $(\mathrm{mm})$ e velocidade $(\mathrm{cm} / \mathrm{s})$, respectivamente. Quanto ao Strain e Strain rate radiais e circunferenciais foram obtidos $24,39 \pm 14,23,1,86 \pm 0,95$ e $-13,69 \pm 6,53$, $-1,01 \pm 0,48$. Portanto, o presente estudo fornece os primei- 
ros dados a respeito do uso desta ferramenta em lobos guarás, permitindo uma quantificação da função miocárdica de forma mais completa nesta espécie.

TERMOS DE INDEXAÇÃO: Canídeo selvagem, lobo-guará, Chrysocyon brachyurus, função cardíaca, função sistólica.

\section{INTRODUCTION}

The maned wolf (Chrysocyon brachyurus) is the largest wild canid of South America and although it is native to the Brazilian cerrado region, it can also be found in Peru, Argentina and Paraguay (Dietz 1985, Estrada et al. 2009, Vasconcellos et al. 2011). Due to difficulties in examining wild animals, there is little information on cardiovascular features in maned wolves. A study by Estrada et al. (2009) demonstrated the radiographic, electrocardiographic and echocardiographic data in captive maned wolves; however there is no data regarding left myocardial contractile function obtained by two-dimensional speckle tracking echocardiography (2D-STE) in this species.

2D-STE is a new echocardiographic modality that allows the assessment of global and regional myocardial function, and has several advantages over tissue Doppler, such as the independence of the insonation angle (Chetboul 2010). This tool provides several parameters that can help to quantify left ventricular myocardial function, including strain (St), which is the magnitude of the deformation (\%) and strain rate (StR), which is the rate of myocardial deformation (1/s) (Pavlopoulos \& Nihoyannopoulos 2008).

In veterinary medicine there have been studies that reported the use of 2D-STE in domestic animals (Chetboul et al. 2007, Schefer et al. 2010, Decloedt et al. 2011, Griffiths et al. 2011, Takano et al. 2011, Wess et al. 2011). In dogs it was demonstrated that 2D-STE is a feasible and useful tool to assess myocardial function (Chetboul et al. 2007, Wess et al. 2011), as it is able to detect early alterations (Takano et al. 2011). However, in wild animals, such as maned wolves, there is no data reporting the use of this echocardiographic modality to evaluate left ventricular myocardial function.

Thus, the aim of this study was to evaluate the myocardial function of a free ranging maned wolf by STE, obtaining its longitudinal, circumferential and radial St and StR, as well as the radial and longitudinal velocity and displacement, given that, to our knowledge, similar data have not been reported previously.

\section{MATERIALS AND METHODS}

A male maned wolf, weighting $29 \mathrm{~kg}$ and about 2 years old, was referred to the cardiology service of the veterinary teaching hospital of the Institution for clinical valuation. Ketamine $(10 \mathrm{mg} / \mathrm{kg} /$ IM) associated with midazolam $(0.5 \mathrm{mg} / \mathrm{kg} / \mathrm{IM})$ was used for sedation and further clinical evaluation and echocardiographic assessment, due to de fact that there is no information at literature about STE in this species.

Echocardiographic studies were performed using an Esaote Mylab $40^{\circledR}$ ultrasound unit equipped with a $4-10 \mathrm{MHz}$ phased-array transducer and simultaneous electrocardiogram.

Standard echocardiographic views were obtained in right and left lateral recumbence (Thomas et al. 1993, Boon 2011). Conventional echocardiographic variables included ventricu- lar measurements taken from the right parasternal short-axis view using the two-dimensional (2D) guided M-mode, such as the left ventricular diastolic diameter (LVDd), left ventricular systolic diameter (LVSd), posterior wall at diastole (PWd) and systole (PWs), inter-ventricular septum at diastole (IVSd) and at systole (IVSs) and fractional shortening (FS \%). Ejection fraction (EF\%) was obtained using the Simpson's modified equation from the right parasternal long axis view. Aortic (Ao) and left atrial (LA) diameter were measured by the 2D mode, and the LA/Ao ratio was calculated. All valves were examined using color Doppler and the velocities over the valves were measured using pulsed wave Doppler examinations. At least five measurements were performed for all echocardiographic variables and the mean value of the measurements was calculated for each parameter.

The 2D echocardiographic loops used for STE analysis were acquired and recorded using the same ultrasound unit as for the standard examinations, as described previously for dogs (Chetboul et al. 2007, Wess et al. 2011). Three to five consecutive heart cycles using a continuous monitoring ECG were stored for off-line analysis. Cine loops were acquired from the left apical four chamber view (LAFCV) and the right parasternal long axis view (RPLAV) to obtain longitudinal function, as well as the right parasternal short axis view (RPSAV) at the papillary muscles level to obtain circumferential and radial function. The frame rate was 50 to 110 frames/s and six measurements were obtained in two different Cine loops (three for each Cine loop) at end-systole for all of the studied variables, following which an average was obtained. Semi-automatic tissue tracking and analysis for STE was performed using Esaote ${ }^{\circledR}$ Xstrain software version 10.1. For myocardial tracking, the endocardial border was marked manually and the epicardial border was then automatically traced by the software, which performed myocardial wall tracking, and velocity vectors were displayed for the region of interest (Fig.1). Manual adjustment of the myocardial wall borders was performed when necessary. Graphics and curves of studied variables were automatically displayed and the peak systolic values of longitudinal St (LSt), StR (LStR), velocity (Lvel), displacement (Ldisp), for radial St (RSt), StR (RStR), velocity (Rvel), displacement (Rdisp), as well as for circumferential St (CSt) and StR (CStR), were shown for the endocardial and epicardial regions of the myocardium (Fig.2).

All data (conventional echocardiography and speckle tracking) were expressed as mean \pm standard deviation (SD). For

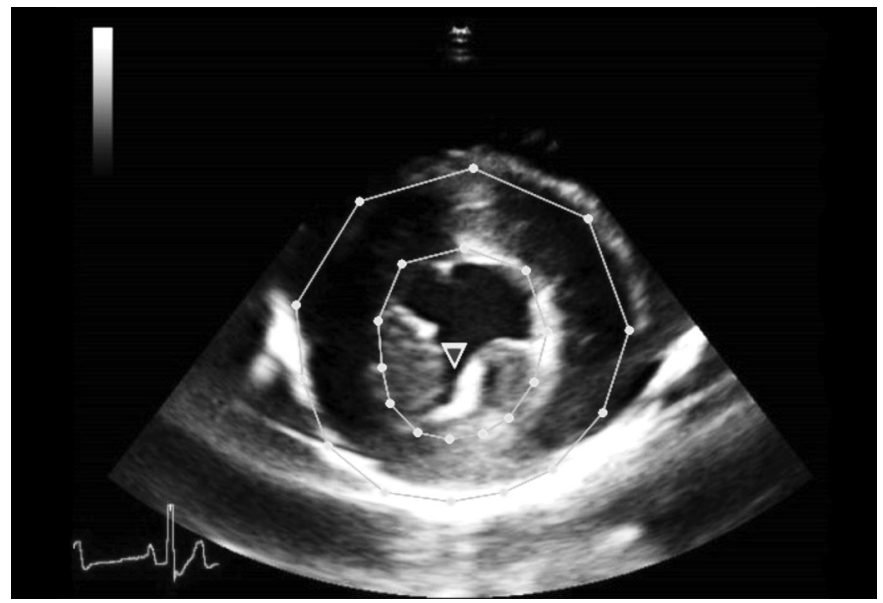

Fig.1. A two-dimensional image from the right parasternal short axis view of a maned wolf. Notice the marked endocardial and epicardial border created by the speckle tracking software. 


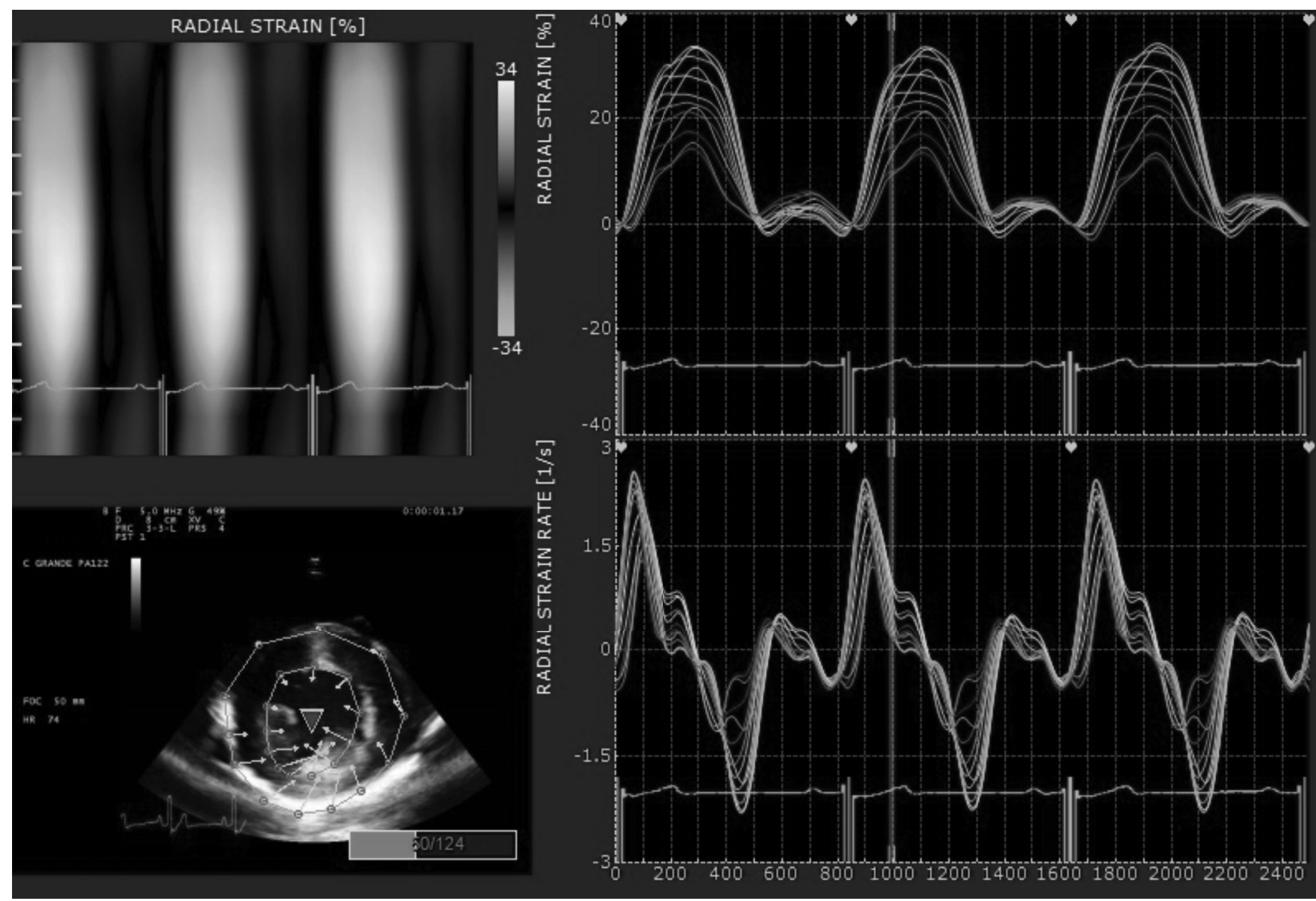

Fig.2. A two-dimensional image from right parasternal short axis view of a maned wolf. Notice the graphics and curves of the radial strain and strain rate automatically displayed after myocardial tracking.

the analysis of data of the variables LSt and LStR in two different echocardiographic views (LAFCV and RPLAV) and at two myocardial regions (epicardium and endocardium), the variables were tested for normality (Kolmogorov-Smirnov), and the values obtained in each view were compared using the Mann-Whitney test $(\mathrm{P}<0.05)$. All analyses were performed using the statistical package SPSS for Windows version $17.0 .^{3}$

\section{RESULTS}

Conventional echocardiography data are displayed as mean and standard deviation (Table 1).

The values of LSt, LStR, Lvel and Ldisp obtained from LAFCV and RPLAV are shown as mean and SD for endocardial and epicardial regions, as well as the global mean. Endocardial values were numerically higher than epicardial ones for all variables in both echocardiographic views, except for LSt at LAFCV. In addition, the global mean for all variables were numerically lower at RPLAV when compared with LAFCV (Table 2).

The values of LSt and LStR were compared between the echocardiographic RPLAV and LAFCV views, and it was observed that LSt was similar at the endocardial region $(\mathrm{P}>0.05)$ and different at the epicardial region $(\mathrm{P}<0.05)$. LStR values were significantly different $(\mathrm{P}<0.05)$ between both views (Table 3).

\footnotetext{
${ }^{3}$ SPSS Statistics 17.0, Rel. 17.0.1. 2008, SPSS Inc., Chicago, IL.
}

Table 4 gives the mean and SD values of RSt, RStR, Rvel, Rdisp, CSt and CStR obtained from RPSAV. It was shown that RSt and RStR were numerically higher than those of CSt and CStR.

Table 1. Variables of standard echocardiography parameters (mean \pm SD) obtained in a maned wolf (Chrysocyon brachyurus)

\begin{tabular}{lc}
\hline \multicolumn{1}{c}{ Variable $^{\mathrm{a}}$} & Values \\
\hline LVDd (cm) & $3.00 \pm 0.08$ \\
LVSd (cm) & $2.00 \pm 0.03$ \\
IVSs (cm) & $1.50 \pm 0.08$ \\
IVSd (cm) & $0.90 \pm 0.01$ \\
PWd (cm) & $0.80 \pm 0.03$ \\
PWs (cm) & $1.15 \pm 0.06$ \\
EF (\%) & $58.00 \pm 2.30$ \\
FS (\%) & $35.00 \pm 1.70$ \\
LA/Ao (cm) & $1.42 \pm 0.06$ \\
Pulmonary Artery flow (m/s) & $0.78 \pm 0.05$ \\
Aortic Flow (m/s) & $0.98 \pm 0.07$ \\
E mitral (m/s) & $0.75 \pm 0.13$ \\
A mitral (m/s) & $0.48 \pm 0.12$
\end{tabular}

${ }^{a}$ LVDd = right ventricular diastolic diameter, LVSd = left ventricular systolic diameter, IVSd = interventricular septum at diastole, IVSs = Interventricular septum at systole (IVSs), PWs $=$ posterior wall at diastole, $\mathrm{PWd}=$ posterior wall at systole, $\mathrm{FS}$ $=$ fractional shortening, $\mathrm{EF}=$ Ejection fraction, $\mathrm{E}$ mitral $=$ trans mitral peak early diastolic velocity, A mitral = transmitral peak late diastolic velocity. 
Table 2. Values of LSt, LStR, Lvel and Ldisp obtained from LAFCV and RPLAV in a maned wolf (Chrysocyon brachyurus) and displayed as mean and SD for endocardial and epicardial regions, as well as, the global mean

\begin{tabular}{lccccc}
\hline View & Region & $\begin{array}{c}\text { Longitudinal } \\
\text { Strain } \\
(\%)\end{array}$ & $\begin{array}{c}\text { Longitudinal } \\
\text { Strain rate } \\
(1 / \mathrm{s})\end{array}$ & $\begin{array}{c}\text { Longitudinal } \\
\text { Displacement } \\
(\mathrm{mm})\end{array}$ & $\begin{array}{c}\text { Longitudinal } \\
\text { Velocity } \\
(\mathrm{cm} / \mathrm{s})\end{array}$ \\
\hline \multirow{3}{*}{ RPLAV $^{\text {a }}$} & Endocardium & $-11.09 \pm 8.71$ & $-1.25 \pm 0.73$ & $1.11 \pm 1.24$ & $2.20 \pm 1.50$ \\
& Epicardium & $-5.00 \pm 4.26$ & $-0.73 \pm 0.45$ & $0.79 \pm 0.94$ & $2.04 \pm 1.71$ \\
& Mean & $-8.94 \pm 7.33$ & $-0.99 \pm 0.66$ & $1.21 \pm 1.11$ & $2.12 \pm 1.59$ \\
LAFCV $^{\mathrm{b}}$ & Endocardium & $-13.14 \pm 9.36$ & $-2.05 \pm 1.30$ & $4.81 \pm 2.88$ & $4.58 \pm 3.69$ \\
& Epicardium & $-13.89 \pm 6.22$ & $-1.14 \pm 0.39$ & $3.87 \pm 2.04$ & $3.15 \pm 2.03$ \\
Mean & $-13.52 \pm 7.88$ & $-1.60 \pm 1.05$ & $4.34 \pm 2.52$ & $3.86 \pm 3.04$ \\
a RPLAV \\
view. Right parasternal long axis view, ${ }^{\mathrm{b}}$ LAFCV = Longitudinal apical four chamber
\end{tabular}

Table 3. Values (mean \pm SD) of LSt e LStR at the myocardial regions (endocardium and epicardium) compared regarding the RPLAV and LAFCV in a maned wolf (Chrysocyon brachyurus)

\begin{tabular}{llll}
\hline \multicolumn{1}{c}{ Region } & \multicolumn{2}{c}{ RPLAV } & P Value \\
\cline { 2 - 2 } & \multicolumn{2}{c}{ Strain $(\%)$} & \\
\hline Endocardium & $-11.09 \pm 8.71$ & $-13.14 \pm 9.36$ & 0.4690 \\
Epicardium & $-5.00 \pm 4.26 \mathrm{~b}$ & $-13.89 \pm 6.22 \mathrm{a}$ & $<0.01^{*}$ \\
& \multicolumn{2}{c}{ Strain Rate $(1 / \mathrm{s})$} \\
Endocardium & $-1.25 \pm 0.73 \mathrm{~b}$ & $-2.05 \pm 1.30 \mathrm{a}$ & $0.0070^{*}$ \\
Epicardium & $-0.73 \pm 0.45 \mathrm{~b}$ & $-1.14 \pm 0.39 \mathrm{a}$ & $<0.01^{*}$
\end{tabular}

$\bar{a}$ Means followed by different letters in the line differ by the Mann-Whitney test $(\mathrm{P}<0.05)$. RPLAV $=$ Right parasternal long axis view, LAFCV $=$ Longitudinal apical four chamber view.

Table 4. Variables of 2D STE obtained from right parasternal short axis view in a maned wolf (Chrysocyon brachyurus)

\begin{tabular}{lc}
\hline \multicolumn{1}{c}{ Variable } & Values \\
\hline Radial Strain (\%) & $24.39 \pm 14.23$ \\
Radial Strain Rate (1/s) & $1.86 \pm 0.95$ \\
Radial Velocity (cm/s) & $2.01 \pm 0.67$ \\
Radial Displacement (mm) & $3.24 \pm 1.78$ \\
Circumferential Strain (\%) & $-13.69 \pm 6.53$ \\
Circumferential Strain Rate (1/s) & $-1.01 \pm 0.48$
\end{tabular}

\section{DISCUSSION}

The values of the diameters and thicknesses of the heart chambers obtained by M-mode were within the normal range, as described by Estrada et al. (2009), indicating an absence of myocardial remodeling.

An EF of 58\%, acquired by Simpson's method, indicated the preservation of systolic function. This method was chosen to determine EF, because it is more accurate for detecting echocardiographic changes when compared to the conventional M-mode (Wess et al. 2010).

Although no data regarding mitral peak velocity was found in the literature, the velocities of transmitral peak early (E) and transmitral peak late (A) diastole are identical to those found by Pereira et al. (2009) and similar to those described in German Shepherd dogs by Muzzi et al. (2006) and Schober \& Fuentes (2001). An E/A ratio greater than 1 and less than 2 indicates a normal relaxation pattern, as seen in this case. In addition, valve insufficiency by Doppler examinations was not observed in this case, however, mitral regurgitation is probably common in older wolves, similarly to dogs (Estrada et al. 2009).
Regarding 2D STE, this tool was found to be adequate and useful for obtaining the myocardial systolic function in the maned wolf. The images acquired were compatible with 2D STE and, due to the fact that the animal was under anesthesia, it facilitated the capture of high quality images. In addition, this technique demonstrates to be easy to perform, since its software automatically provides the measurements of the myocardial variables.

The longitudinal variables St, StR, velocity and displacement obtained from LAFCV were similar to those obtained in dogs by Wess et al. (2011), being the global means of our study $-13.52 \pm 7.88,-1.60 \pm 1.05,3.86 \pm 3.04,4.34 \pm 2.52$, respectively. For all of the variables obtained in this plane, the endocardial values were higher than the epicardial, except for LSt, which was similar in both regions, a fact previously reported in humans by Leitman et al. (2010). In a study by Decloedt et al. (2011), the values observed for horses were much higher than those observed for the wolf in our study. This can be justified by anatomical differences, such as the size of the heart.

In our study, the longitudinal variables were acquired from both the RPLAV and LAFCV, due to the fact that there are no studies comparing data obtained from these views, given that the RPLAV is not commonly used to obtain longitudinal function. Data demonstrated that there is no difference for endocardial LSt in both planes; however, for the other variables, significantly lower values were observed for RPLAV compared to LAFCV, which is the standard plane to obtain left ventricular myocardial longitudinal function. These data show that the RPLAV is not adequate to obtain LStR, Ldisp and Lvel, but is a good choice to measure LSt. Nonetheless, a study with a large population of maned wolves is necessary to disclose the reliability of acquiring longitudinal function using the RPLAV.

Radial and circumferential variables were obtained using RPSAV. The values of RSt were lower than previous studies in dogs (Chetboul et al. 2007, Takano et al. 2011) and in horses (Schwarzwald et al. 2009), which can be attributed to technical differences between the ultrasound units, since the software used in those studies, was based on a different algorithm (block-matching), while in our study was used an optical flow method. Species particularities and anatomical differences, as body weight and heart size, also can influence the results. On the other hand, the values found were similar to those observed in normal human 
subjects (Hurlburt et al. 2007). Also, the values obtained for CSt were found to be lower than previous data in dogs (Takano et al. 2011) and in humans (Hurlburt et al. 2007), yet similar to data reported in horses (Schwarzwald et al. 2009). The variables RStR and CStR were similar to those obtained by Schwarzwald et al. (2009) in a study of horses. In that same study Rdisp was assessed, and was shown to be much higher than the values found in our study.

The limitations of this investigation must be clarified. Firstly, the study was performed on a single wolf, meaning that a larger study population needs to be investigated in order to establish more accurate reference values and to identify the influences of sex and age on 2D STE parameters in maned wolves. Nonetheless, this study provides preliminary reference values for longitudinal and radial St, StR, velocity and displacement, as well as circumferential St and StR for a maned wolf, and also demonstrated the feasibility of using the technique in this species. Another consideration is the fact that the sedation protocol might influence the myocardial function and ketamine is likely to reduce the contractile function, as reported previously in other species, such as domestic cats and oncilla (Leopardus tigrinus) (Dümel et al. 1996, Carvalho et al. 2007).

\section{CONCLUSION}

2D STE can be considered a reliable technique for measuring longitudinal, radial and circumferential myocardial function in maned wolves. These measurements provide new insights into ventricular deformation and motion, allowing a more complete quantification of myocardial function in this species. However, further studies should be performed in a larger population of healthy and diseased wolves to evaluate the role and reliability of this technique in this species.

Acknowledgments.- To Fundação de Amparo a Pesquisa do Estado de Minas Gerais (FAPEMIG), Coordenação de Aperfeiçoamento de Pessoal de Nível Superior (CAPES) and to Conselho Nacional de Desenvolvimento Científico e Tecnológico (CNPq) for the financial support.

\section{REFERENCES}

Boon J.A. 2011. The two-dimensional echocardiographyc exam, p.37-100. In: Boon J.A. (Ed.), Veterinary Echocardiography. Wiley-Blackwell, Iowa.

Carvalho P.S.L., Pereira G.G., Petrus L.C., Soares E.C., Michina L.E. \& Larsson M.H.M.A. 2007. Evaluation of some echocardiographic parameters of Oncilla (L. tigrinus), kept in captivity and submitted to anesthesia with xilazine and ketamine. Arq. Bras. Med. Vet. Zootec. 59:695-699.

Chetboul V., Serres F., Gouni V., Tissier F. \& Pouchelon J.L. 2007. Radial strain and strain rate by two-dimensional speckle tracking echocardiography and tissue velocity based technique in the dog. J. Vet. Cardiol. 9:69-81.

Chetboul V. 2010. Advanced techniques in echocardiography in small animals. Vet. Clin. North Am., Small Anim. Pract. 40:529-543.
Decloedt A., Verheyen T., Sys S., De Clercq D. \& Van Loon G. 2011. Quantification of left ventricular longitudinal strain, strain rate, velocity, and displacement in healthy horses by 2-dimensional speckle tracking. J. Vet. Intern. Med. 25:330-338

Dietz J.M. 1985. Chrysocyon brachyurus. Mammalian Species 234:1-4.

Dümmel C., Neu H., Hüttig A. \& Failing K. 1996. Echocardiographic reference ranges of sedated cats. Tierärztl. Praxis 24:190-196.

Estrada A.H., Gerlach T.J., Schmidt M.K., Siegal-Willott J.L., Atkins A.L., Gilder J.V., Cintino S.B. \& Padilla L.R. 2009. Cardiac evaluation of clinically healthy captive maned wolves (Chrysocyon brachyurus). J. Zoo Wildl. Med. 40:478-486.

Griffiths L.J., Fransioli J.R. \& Chigerwe M. 2011. Echocardiographic assessment of interventricular and intraventricular mechanical synchrony in normal dogs. J. Vet. Cardiol. 13:115-126.

Hurlburt H.M., Aurigemma G.P., Hill J.C., Narayanan A., Gaasch W.H., Vinch C.S., Meyer T.E. \& Tighe D.A. 2007. Direct ultrasound measurement of longitudinal, circumferential, and radial strain using 2-dimensional strain imaging in normal adults. Echocardiography 24:723-731.

Leitman M., Lysiansky M., Lysyansky P., Friedman Z., Tyomkin V., Fuchs T., Adam D., Krakover R. \& Vered Z. 2010. Circumferential and longitudinal strain in 3 myocardial layers in normal subjects and in patients with regional left ventricular dysfunction. J. Am. Soc. Echocardiogr. 23:64-70.

Muzzi R.A.L., Muzzi L.A.L., Araujo R.B. \& Cherem M. 2006. Echocardiographic indices in normal German Shepherd dogs. J. Vet. Sci. 7:193-198.

Pavlopoulos H. \& Nihoyannopoulos P. 2008. Strain and strain rate deformation parameters: from tissue Doppler to 2D speckle tracking. Int. J. Cardiovasc. Imaging 24:479-491.

Pereira G.G., Petrus L.C., Santos A.L.F., Yamaki F.L \& Larsson M.H.M.A. 2009. Evaluation of left ventricular diastolic echocardiographic parameters in healthy dogs by pulsed-wave Doppler. Pesq. Vet. Bras. 29:291-294.

Schefer K.D., Bitschnau C., Weishaupt M.A. \& Schwarzwald CC. 2010. Quantitative analysis of stress echocardiograms in healthy horses with 2-dimensional (2D) echocardiography, anatomical M-mode, tissue Doppler imaging, and 2D speckle tracking. J. Vet. Intern. Med. 24:918-931.

Schober K.E. \& Fuentes V.L. 2001. Effects of age, body weight, and heart hate on transmitral and pulmonary venous flow in clinically nor-mal dogs. Am. J. Vet. Res. 62:1447-1454.

Takano H., Fujii Y., Yugeta N., Takeda S. \& Wakao Y. 2011. Assessment of left ventricular regional function in affected and carrier dogs with Duchene muscular dystrophy using speckle tracking echocardiography. BMC Cardiovasc. Disord. 11:2-8.

Thomas W.P., Gaber C.E., Jacobs G.J., Kaplan P.M., Lombard C.W., Moise N.S. \& Mases B.L. 1993. Recommendations for standards in transthoracic two-dimensional echocardiography in the dog and cat. Echocardiography Committee of the Specialty of Cardiology, American College of Veterinary Internal Medicine. J. Vet. Intern. Med. 7:247-252.

Vasconcellos A.S., Chelini M.O.M., Palme R., Guimarães M.A.B.V., Oliveira C.A. \& Ades C. 2011. Comparison of two methods for glucocorticoid evaluation in maned wolves. Pesq. Vet. Bras. 31:79-83.

Wess G., Mãuer J., Simak J. \& Hartmann K. 2010. Use of Simpson's method of disc to detect early echocardiographic changes in Doberman Pinschers with dilated cardiomyopathy. J. Vet. Intern. Med. 24:1069-1076.

Wess G., Keller L.J., Klausnitzer M., Killich M. \& Hartmann K. 2011. Comparison of longitudinal myocardial tissue velocity, strain, and strain rate measured by two-dimensional speckle tracking and by color tissue Doppler imaging in healthy dogs. J. Vet. Cardiol. 13:31-43. 